\title{
THE PHOSPHATIDES OF THE KIDNEY
}

By HUGH MacLEAN.

\section{From the Lister Institute, Bio-Chemical Department}

(Received June 20th, 1912)

The researches of Erlandsen ${ }^{1}$ on the phosphatides of cardiac muscle showed that the older methods of extracting tissues with alcohol did not suffice to isolate pure substances, and that the so-called lecithin obtained was really a mixture. According to this investigator the phosphatides contained in the ethereal extract of dried cardiac muscle consisted chiefly of two substances-lecithin with a nitrogen : phosphorus ratio of $1: 1$, and cuorin with a nitrogen : phosphorus ratio of $1: 2$. Another ether soluble substance, however, was present in large amount, but was incapable of being extracted by ether until the tissue had undergone a preliminary treatment with alcohol. This behaviour towards ether suggested that this substance was present in the tissue in some combination which was split up by the alcohol, or that the ether did not penetrate the dried tissue sufficiently well to extract it. Erlandsen extracted this substance by means of alcohol after a thorough preliminary treatment of the tissue with ether, and found that the greater part of the alcoholic extract consisted of a phosphatide which differed materially in constitution from lecithin and cuorin, and contained in its molecule two atoms of nitrogen to one of phosphorus.

These observations of Erlandsen strongly supported the combination view, for if the ether were incapable of penetration as the result of purely physical conditions, it is difficult to understand why there should be any material difference in the nature of the phosphatide obtained in the ether and alcohol extracts respectively.

These results with cardiac muscle suggested that other tissues probably behave in a similar manner towards ether and alcohol, and in order to determine this the following investigation of kidney phosphatides was carried out.

\section{Preparation of Material}

Horse kidneys were used on account of their cheapness and the ease with which large supplies could be obtained. In the first experiment fifteen fresh kidneys were washed with normal saline solution and freed 
as much as possible from adherent fat and fibrous tissue. They were then passed through a mincing machine, and the finely divided tissue dried on a glass plate by means of a fan at a temperature of about $30^{\circ}$. The dried substance obtained was now dried in a desiccator over sulphuric acid and finely ground in a mill to a fine powder.

\section{Extraction with Ether}

The dried powder, which weighed 2075 grams, was shaken up with ether in a dark, well-stoppered bottle, which contained $\mathrm{CO}_{2}$ in order to prevent oxidation. After extracting six times, the ethereal extracts were evaporated to very small bulk under reduced pressure and at room temperature. The residue, which now formed a syrupy mass, was treated with a large excess of acetone and the mixture allowed to stand for half an hour. The precipitate which formed was separated from the ether-acetone liquid, dissolved in some pure ether, and again precipitated by acetone. It was then thoroughly washed with acetone and dried in vacuo. By this treatment with acetone, most of the ordinary fat and cholesterol was separated. In separating phosphatides from fat by means of acetone, it is important to separate the precipitate from the ether-acetone solution in a short time, for though acetone first precipitates phosphatides from an ethereal solution, it gradually precipitates such substances as neutral fat and certain saturated fatty acids. The crude phosphatide obtained weighed about 29 grams.

\section{Treatment of Crude Phosphatide of Ethereal Extract}

The crude extract was dissolved in about 150 c.c. ether, and an opalescent solution obtained which on centrifuging yielded a fair amount of a white precipitate and a clear dark amber-coloured fluid. The phosphatides were precipitated from this solution by the addition of excess of acetone, and dried in vacuo. This process of dissolving in ether, centrifuging and treating with acetone was repeated four times. All the white precipitates obtained on centrifuging were mixed together, and for purposes of reference may be called 'white substance.'

The phosphatide residue was dissolved in 100 c.c. ether and gave an almost clear solution; to this 500 c.c. absolute alcohol were added, and the mixture left to stand in an ice-room overnight. Immediately on the addition of the alcohol, a precipitate formed which became more marked on standing. After sixteen hours, this precipitate was separated by 
filtration and washed thoroughly with alcohol. It was then dissolved in ether, precipitated by acetone and dried in vacuo.

An ether-alcohol solution $(b)$ and a precipitate $(a)$ were thus obtained.

\section{Treatment of Alcohol-insoluble Substance $(a)$}

This substance was treated with alcohol at $45^{\circ} \mathrm{C}$., and the residue dried in vacuo, dissolved in ether and precipitated by acetone. After drying it was re-dissolved in freshly distilled hot ethyl acetate and allowed to stand for some hours in the ice-room, when a substance of syrupy consistency fell out. This treatment with ethyl acetate was repeated and the syrup obtained dried and analysed.

All the above operations were carried out as far as possible in an atmosphere of $\mathrm{CO}_{2}$ to prevent oxidation; at the same time an endeavour was made to prevent any deleterious action of light by the use of dark glass desiccators and bottles.

Treatment of Ether-Alcohol Solution (b)

This liquid was evaporated under reduced pressure at a temperature of about $35^{\circ} \mathrm{C}$., and a small amount of a substance obtained, which was dissolved in pure ether and precipitated by acetone. This substance, which represents ordinary 'lecithin,' was dried and analysed.

Treatment of ' White Substance' obtained by Centrifuge

This substance was first treated with cold alcohol, when a small amount of it dissolved. On filtering, the residue was extracted with hot alcohol, when a considerable amount easily went into solution, while part seemed quite insoluble. The solution was filtered hot and the filtrate left to stand at room temperature, when a white flocculent substance separated out. This substance was filtered off, again dissolved in hot alcohol and filtered hot as before. The flocculent substance obtained was thoroughly washed with cold ether, in which it was practically insoluble; it was then treated with hot ether and dried. The part insoluble in hot alcohol was composed chiefly of inorganic salts and was not further investigated.

From the ethereal extract of kidney, three substances were now obtained.

(1) A small amount of a substance soluble in hot alcohol but insoluble in ether. 'White substance.'

(2) A substance soluble in alcohol and in ether-lecithin.

(3) A substance insoluble in alcohol but soluble in etherCuorin. 
It is interesting to note that only a very small amount of ordinary lecithin was found. The greater part of the ethereal extract was composed of the alcohol insoluble portion, of which about 13 grams were isolated, while only about 2.5 grams lecithin were obtained.

\section{(1) 'White substance' separated by centrifuge}

The total amount of this substance obtained was only $0.55 \mathrm{gram}$. Op analysis it gave the following figures. Nitrogen and phosphorus were estimated by the methods of Kjeldahl and Neumann respectively.

\section{Nitrogen}

0.3125 gm. used 6.6 c.c. $\mathrm{N} / 10 \mathrm{H}_{2} \mathrm{SO}_{4}=2 \cdot 9$ per cent. Nitrogen.

Phosphorus

0.1120 gm. used 7 c.c. $\mathrm{N} / 2 \mathrm{NaOH}=3 \cdot 46$ per cent. Phosphorus.

$$
\mathrm{N}: \mathrm{P}=1.86: 1 \text {. }
$$

While it is probable that this substance was not quite pure, the small quantity obtained rendered it very difficult to get quite accurate figures; it is practically a diamino-monophosphatide, and from its general appearance and properties is probably of the same nature as a similar substance described under the alcoholic extract of the kidneys.

Thus it was practically insoluble in cold ether and only very slightly soluble in cold alcohol, in hot alcohol it dissolved with ease and separated out on cooling as a flocculent substance which on drying formed a white non-hygroscopic powder. In chloroform and benzene it dissolved easily, especially on heating; cold glacial acetic acid dissolved it with some difficulty, but on heating it dissolved readily. From these solutions it was precipitated by acetone. In general it bears a close resemblance to a substance described by Stern and Thierfelder, ${ }^{2}$ and isolated by then from egg yolk.

\section{(2) Alcohol and ether soluble substance-Lecithin}

This fraction had all the properties of the mono-amino-monophosphatide-lecithin. It was of somewhat waxy consistence, yellowish white in appearance and very hygroscopic. In vacuo it dried very quickly to constant weight, but was sticky to the touch and incapable of being powdered. In ether, alcohol, benzene, chloroform and petroleum ether it dissolved with ease and was readily precipitated from these solutions by acetone. In ether it gave a slightly opalescent solution which cleared up in a short time to a clear dark liquid. 


\section{Analyses}

$0.1021 \mathrm{gm}$. substance gave $0.2385 \mathrm{gm} . \mathrm{CO}_{2}=63.7$ per cent. C. and $0.1040 \mathrm{gm} . \mathrm{H}_{2} \mathrm{O}=11 \cdot 3$ per cent. $\mathrm{H}$.

Nitrogen

$0.3219 \mathrm{gm}$. used 4.5 c.c. $\mathrm{N} / 10 \mathrm{H}_{2} \mathrm{SO}_{4}=2.0$ per cent.

$0.6123 \mathrm{gm}$. used 8.5 c.c. $\mathrm{N} / 10 \mathrm{H}_{2} \mathrm{SO}_{4}=1.94$ per cent.

Average $=1.97$ per cent. Nitrogen.

\section{Phosphorus}

$0.3202 \mathrm{gm}$. used $21.8 \mathrm{~N} / 2 \mathrm{NaOH}=3.77$ per cent.

$0.2151 \mathrm{gm}$. used 16 c.c. $\mathrm{N} / 2 \mathrm{NaOH}=3 \cdot 9$ per cent.

$$
\begin{gathered}
\text { Average }=3.83 \text { per cent. } \\
N: P=1.14: 1 .
\end{gathered}
$$

It is probable that this lecithin was not quite pure, as the ratio of nitrogen to phosphorus is somewhat too high. In general, however, it agrees well with the lecithins described by Stern and Thierfelder, ${ }^{2}$ and by Erlandsen, ${ }^{1}$ as the following table shows.

\section{Analyses of Differenty Lecithins}

\begin{tabular}{lccccc} 
& & & $\begin{array}{c}\text { Lecithin from horse } \\
\text { kidney }\end{array}$ & $\begin{array}{c}\text { Lecithin from heart } \\
\text { muscle (Erlandsen) }\end{array}$ & $\begin{array}{c}\text { Lecithin from egg yolk } \\
\text { (Stern and Thierfelder) }\end{array}$ \\
C & $\ldots$ & $\ldots$ & $63 \cdot 7$ & $66 \cdot 29$ & $64 \cdot 63$ \\
H & $\ldots$ & $\ldots$ & $11 \cdot 3$ & $10 \cdot 17$ & 10.96 \\
N & $\ldots$ & $\ldots$ & 1.97 & $1 \cdot 87$ & 2.08 \\
P & $\ldots$ & $\ldots$ & 3.83 & 3.95 & 3.97 \\
\hline N : P ratio & $\ldots$ & $1 \cdot 14: 1$ & $1: 1$ & $1 \cdot 16: 1$
\end{tabular}

On hydrolysis a substance which gave the reactions of glycerophosphoric acid was obtained as well as choline, but, as in other lecithins, the yield of choline obtained was considerably less than the theoretical amount.

In order to determine the iodine value of the lecithin, a small amount was prepared specially for the purpose, as it was found that even when preserved in as complete a vacuum as possible, the iodine number gradually diminished. This specially prepared substance was isolated and purified as quickly as possible, and gave an iodine value of 85 . The free fatty acids obtained from this sample by saponification with alcoholic potash in an atmosphere of hydrogen gave an iodine value of 113 . It is probable, however, despite the precautions taken, that a certain amount of oxidation had occurred, so that the value obtained is perhaps somewhat low. 
No saturated acids were found while bromine derivatives of acids, having three or more unsaturated bonds, were prepared.

The nature of the acids present in lecithin and other phosphatides will be discussed in a later paper.

(3) Substance insoluble in alcohol but soluble in ether-Cuorin

While a comparatively small amount of lecithin was found in the ethereal extract, a considerable amount of cuorin was present.

It was obtained as a yellowish transparent substance, which was exceedingly hygroscopic, but dried quickly in vacuo to a hard solid mass, which was easily reduced to a fine powder. It dissolved at room temperature in ether, petroleum-ether, carbon disulphide, and chloroform; while it was practically insoluble in cold ethyl acetate, it dissolved easily on heating; on cooling it separated out as a syrupy mass. In cold and hot alcohol it was quite insoluble. This substance oxidised with great readiness, so that it was difficult to keep it unchanged for any length of time; as it oxidised, it gradually changed its solubility, and, after a time, it became insoluble in ether and somewhat soluble in water.

It was precipitated by acetone out of its ethereal solution; platinum chloride and cadmium chloride gave insoluble combinations.

The iodine value of the freshly prepared substance was 100 , while that of the fatty acids was 133 . Even when kept in an evacuated desiccator the iodine value gradually diminished, so that after a fortnight it was only 83; on exposure to the air it decreased in about a week to 52 .

\section{Analyses}

0.1216 gm. substance gave 0.2695 gm. $\mathrm{CO}_{2}=60 \cdot 4$ per cent. C. and $0.1120 \mathrm{gm} . \mathrm{H}_{2} \mathrm{O}=10 \cdot 2$ per cent. $\mathrm{H}$.

Nitrogen

$0.5216 \mathrm{gm}$. used $3.8 \mathrm{~N} / 10 \mathrm{H}_{2} \mathrm{SO}_{4}=1.02$ per cent.

$0.6210 \mathrm{gm}$. used $4.7 \mathrm{~N} / 10 \mathrm{H}_{2} \mathrm{SO}_{4}=1.06$ per cent. Average $=1.04$ per cent. $\mathrm{N}$.

Phosphorus

$0.3105 \mathrm{gm}$. used $25 \cdot 2$ c.c. $\mathrm{N} / 2 \mathrm{NaOH}=4.49$ per cent.

$0.2108 \mathrm{gm}$. used 16.8 c.c. $\mathrm{N} / 2 \mathrm{NaOH}=4.41$ per cent.

Average $=4 \cdot 45$ per cent. $P$.

$\mathrm{N}: \mathrm{P}=1: 1 \cdot 93$.

A comparison of this substance with the cuorin described by Erlandsen shows that it agrees exactly with the analysis of cuorin... A 
somewhat similar substance has been isolated by Baskoff from the liver, but though its properties are similar to those of cuorin, it gave somewhat different figures on analysis. It is probable that this substance, which Baskoff called heparphosphatid, was not isolated in a pure form, and the fact that it contains sulphur strengthens this idea.

A somewhat similar substance which $I$ isolated from egg yolk ${ }^{3}$ differed in its percentage of nitrogen and phosphorus from this substance, but had a $\mathrm{N}: \mathrm{P}$ ratio of exactly $1: 2$.

Comparison of Analyses of Differefet Mono-Amino-diphosphatides Hitherto Isolated

\begin{tabular}{ccccccc} 
& & $\begin{array}{c}\text { Substance from } \\
\text { horse kidney } \\
\text { (MacLean)! }\end{array}$ & $\begin{array}{c}\text { Cuorin from heart } \\
\text { muscle } \\
\text { (Erlandsen) }\end{array}$ & $\begin{array}{c}\text { Heparphosphatid } \\
\text { from liver } \\
\text { (Baskoff) }\end{array}$ & $\begin{array}{c}\text { Mono-amino- } \\
\text { diphosphatide } \\
\text { from egg yolk } \\
\text { (MacLean) }\end{array}$ \\
C & $\ldots$ & $\ldots$ & 60.4 & $61 \cdot 33$ & $61 \cdot 12$ & $59 \cdot 12$ \\
H & $\ldots$ & $\ldots$ & 10.2 & 9.02 & 8.95 & $9 \cdot 44$ \\
N & $\ldots$ & $\ldots$ & 1.04 & 1.01 & 1.23 & 0.812 \\
P & $\ldots$ & $\ldots$ & $4 \cdot 45$ & $4 \cdot 47$ & 4.0 & 3.59 \\
\hline N : P & $\ldots$ & $1: 2$ & $1: 2$ & $1: 1.5$ & $1: 2$
\end{tabular}

These figures indicate that the substance obtained from horse kidney is the same as that obtained from heart muscle by Erlandsen.

On saponification with alcoholic potash, 60 per cent. of the weight of cuorin was obtained as fatty acids, which were solid at room temperature and melted at about $45^{\circ}$.

They were composed of one solid saturated acid and two unsaturated liquid acids; the solid acid was found to be stearic, while the liquid acids, as in the case of lecithin, gave bromination products, indicating the presence of acids having three or more double bonds. They will be discussed, along with the acids of lecithin, in a later paper.

The other cleavage products consisted of a substance having the reactions of glycerophosphoric acid, though the amount of barium obtained on analysis of the barium salt did not quite agree with the theoretical amount. Only a very small amount of a basic substance precipitated by platinum chloride could be obtained, so it is certain that the nitrogen is not represented by choline.

From these results it is clear that the acetone insoluble phosphatides present in the ethereal extract of horse kidneys are of the same nature as those described by Erlandsen from heart muscle. In spite of the observation of Fraenkel that he could not obtain any evidence of the presence of lecithin in the kidney, there can be no doubt that a small amount is present in the ethereal extract. It will be shown later that 
quite a considerable amount of lecithin is present in the alcoholic extract.

The three substances present in the ethereal extract of kidney are therefore lecithin, cuorin and a diamino-monophosphatide. Cuorin was found in greatest amount, while only a small quantity of lecithin and a very small amount of the diamino-monophosphatide was isolated.

\section{The Alcoholic Extract}

Our knowledge of the phosphatides present in the alcoholic extract of the different tissues is very unsatisfactory. According to Erlandsen, by far the greater part of the extract consists of a phosphatide having a $\mathrm{N}: \mathrm{P}$ ratio of $2: 1$.

This observation was based on the analyses of cadmium chloride compounds, but he was unable to isolate the substance in a free state. An attempt to liberate the phosphatide from the cadmium compound was unsuccessful, the substance obtained differing in its constitution from the theoretical composition deduced from the cadmium salt. In order to explain this result, Erlandsen assumed that the manipulations required for setting free the phosphatide resulted in a partial decomposition of this body, but it is interesting to observe that the $N: P$ ratio of the substance obtained was $1.48: 1$.

Baskoff extracted the liver, first with alcohol, then with ether, and lastly with 96 per cent. alcohol. This second alcoholic extract was evaporated to small bulk in vacuo, and the residue dissolved in a small amount of alcohol. An insoluble fraction remained which consisted chiefly of inorganic substances. The alcoholic filtrate was now evaporated to dryness, and the residue extracted with ether, when a white substance was obtained and filtered off. This substance contained $4 \cdot 16$ per cent. nitrogen and 2.52 per cent. phosphorus $=\mathrm{N}: \mathrm{P} 3.68: 1$, and was regarded by Baskoff as a jecorin-like substance. The ethereal solution was concentrated and precipitated with acetone, the precipitate dissolved in ether and some alcohol added. A precipitate was now obtained which on analysis gave 4.703 per cent. nitrogen and 1.93 per cent. phosphorus $=\mathrm{N}: \mathrm{P} 5.07: 1$.

After filtering off this substance the ether-alcohol solution was evaporated to dryness and the residue dissolved in ether and precipitated by acetone. This fraction constituted by far the greater part of the alcohol soluble substance; it was once again purified by ether and acetone. This substance was now analysed and compared with a corresponding body obtained by Erlandsen from heart muscle. 


\section{THE PHOSPHATIDES OF THE KIDNEY}

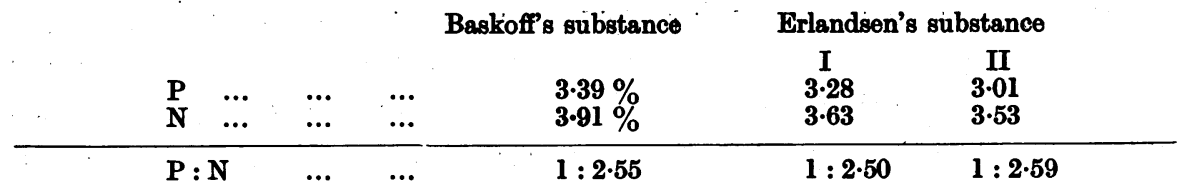

These figures show that the substances contain nearly the same amount of nitrogen and phosphorus, the $\mathrm{N}: \mathrm{P}$ ratio in each case being practically the same.

From this substance Erlandsen succeeded in isolating a cadmium chloride compound which gave a $\mathrm{N}: \mathrm{P}$ ratio of exactly $2: 1$, while on the contrary Baskoff's cadmium compound had a $\mathrm{N}: \mathrm{P}$ ratio of $1.57: 1$.

These results suggest that the substances thus obtained were not quite pure, and evidence in support of this will be brought forward later. Baskoff agrees with Erlandsen that the alcohol extract contains phosphatides with a higher nitrogen content than those of the ether extract, though he was unable fully to substantiate Erlandsen's results. It is noteworthy that both the jecorin-like substances and the alcohol soluble phosphatides all contain a high percentage of nitrogen.

\section{Treatment of Ether Extracted Tissue}

After thorough treatment with ether, the kidney substance was extracted with alcohol, first at room temperature and then at $40^{\circ} \mathrm{C}$. This was repeated six times, the combined alcohol extracts evaporated off under reduced pressure and the residue extracted with pure ether. A considerable amount of substance was obtained which gave a very opalescent solution with ether. This was left to stand, the supernatant fluid treated with excess of acetone and the crude phosphatide obtained dried in vacuo.

\section{Treatment of Crude Phosphatide Mixture}

The dried crude substance, which weighed about 50 grams, was now dissolved in ether, and gave a somewhat opalescent solution which soon cleared up, leaving a small amount of a white insoluble precipitate. This was filtered off, the ethereal solution precipitated by acetone, the precipitate dried and extracted with a small amount of absolute alcohol. A very turbid liquid was obtained. On centrifuging, a white precipitate $(a)$ separated, and a clear alcoholic solution was obtained.

This solution was evaporated to dryness under reduced pressure at a low temperature, and the residue taken up in alcohol. The alcoholic 
solution was at first somewhat turbid, but soon became quite clear. On standing in the ice-room overnight a white substance was precipitated which, on separation by the centrifuge, was washed twice with a small amount of cold alcohol $=$ white precipitate $(b)$.

This precipitate $(b)$ was now mixed with precipitate $(a)$, and the whole extracted twice with hot acetone. The residue was only partly soluble in ether and in alcohol.

On analysis it was found to contain 6.2 per cent. nitrogen and 1.5 per cent. phosphorus; it was not further examined.

The alcoholic solution was again evaporated to dryness, and the residue dissolved in a very small amount of alcohol by the aid of gentle heat. On standing in the ice-room overnight some more white substance separated out. After filtering, the alcoholic extract was evaporated to small bulk and about five times its volume of pure ether added, a precipitate consisting partly of a white powder and partly of a slimy mass formed and was filtered off. This precipitate was washed with ether, in which the white substance remained in suspension while the slimy portion remained at the bottom of the vessel.

The ethereal suspension was syphoned off and left to stand, when the white particles fell to the bottom of the glass. On separating the ether a perfectly white substance was obtained which, on drying, formed a white solid mass which was easily broken up to a white powder $=$ white powder $(d)$.

The slimy mass obtained was dried in vacuo $=$ substance $(f)$. The alcohol-ether filtrate was evaporated to dryness and the residue dissolved in ether, when a perfectly clear solution was obtained after standing a short time. This was precipitated by acetone, the precipitate again dissolved in ether and reprecipitated by acetone. The substance obtained gave a clear solution in alcohol, while in ether it was at first somewhat cloudy, but on standing soon became quite clear.

This substance was now dissolved in alcohol and three times its volume of acetone added. A precipitate at once formed which was filtered off, dissolved in ether, precipitated by acetone, and dried. This fraction constituted by far the greater part of the phosphatides of the alcoholic extract $=$ phosphatide $(m)$. On adding more acetone to the above acetone-alcohol solution a slight cloudiness was in evidence, but on the addition of great excess of acetone a white sticky substance separated, which differed in appearance from substance $(m)$ above. This will be referred to as phosphatide $(p)$. 
As it was thought that these two fractions might differ in constitution, they were dried and analysed separately. The fraction $(m)$, which was at first easily soluble in alcohol, became partly insoluble after some time, while precipitate $(p)$ remained soluble for a much longer time.

From the alcoholic extract four fractions were now obtained.

(1) Lecithin-like substance $(m)$ about 16 grams.

(2) Lecithin-like substance $(p)$,, 2.5 grams.

(3) White substance ‥ (d) , $3 \cdot 1$ grams.

(4) Slimy mass $\quad \ldots \quad(f) \quad, \quad 3.5$ grams.

\section{Subtance $(m)$}

This was obtained as a yellowish white lecithin-like substance soluble in alcohol, ether, chloroform, benzene and petroleum-ether. It dried quickly to constant weight, was very hygroscopic, and had all the general properties of lecithin.

Nitrogen-

\section{Analyses}

$1.0460 \mathrm{gm}$. used $36 \cdot 2 \mathrm{~N} / 10 \mathrm{H}_{2} \mathrm{SO}_{4}=4.9$ per cent.

$0.9027 \mathrm{gm}$. used $31.5 \mathrm{~N} / 10 \mathrm{H}_{2} \mathrm{SO}_{4}=4.9$ per cent.

Average $=4.9$ per cent. $\mathrm{N}$.

Phosphorus-

0.4172 gm. used 27.48 c.c. $\mathrm{N} / 2 \mathrm{NaOH}=3.65$ per cent.

$0.4691 \mathrm{gm}$. used 30 c.c. $\mathrm{N} / 2 \mathrm{NaOH}=3.54$ per cent.

Average $=3.59$ per cent. $P$.

$\mathrm{N}: \mathrm{P}=3: 1$.

From the nitrogen phosphorus ratio it seemed as if this might possibly be a pure phosphatide, and to determine this the cadmium chloride compound was prepared.

Five grams of the substance were dissolved in alcohol, and an alcoholic solution of cadmium chloride added as long as a precipitate formed. The alcohol was then filtered off, the precipitate washed thoroughly with alcohol, dried and analysed.

\section{Nitrogen-}

$$
\text { Analyses of cadmium chloride salt }
$$

$0 \cdot 7028 \mathrm{gm}$. used $11 \cdot 8$ c.c. $\mathrm{N} / 10 \mathrm{H}_{2} \mathrm{SO}_{4}=2 \cdot 35$ per cent.

$0 \cdot 3504 \mathrm{gm}$. used 6 c.c. $\mathrm{N} / 10 \mathrm{H}_{2} \mathrm{SO}_{4}=2 \cdot 4$ per cent.

$$
\text { Average }=2 \cdot 3 \text { per cent. } N \text {. }
$$




\section{Phosphorus-}

0.3264 gm. used 19.4 c.c. $\mathrm{N} / 2 \mathrm{NaOH}=3.3$ per cent.

$0 \cdot 2603$ gm. used 15.9 c.c. $\mathrm{N} / 2 \mathrm{NaOH}=3 \cdot 4$ per cent.

$$
\begin{gathered}
\text { Average }=3.35 \text { per cent. } \mathbf{P} . \\
\mathbf{N}: \mathbf{P}=\mathbf{1} \cdot 5: \mathbf{1} .
\end{gathered}
$$

From this result it was obvious that the substance $(m)$ was not a chemical entity, and that the precipitation with cadmium chloride had separated off a large amount of the nitrogen. Analysis of 100 c.c. of the alcoholic filtrate obtained from the cadmium chloride precipitation showed that a very great excess of nitrogen was present. As cadmium chloride does not precipitate phosphatides quantitatively out of alcoholic solution, it is probable that part of the nitrogen was accounted for in this way. On the other hand, some nitrogenous substance free from phosphorus must have been present.

\section{Analysis of filtrate}

50 c.c filtrate used 31.5 c.c. $\mathrm{N} / 10 \mathrm{H}_{2} \mathrm{SO}_{4}=0.88$ per cent. $\mathrm{N}$. 50 c.c. filtrate used $12 \cdot 6$ c.c. $\mathrm{N} / 2 \mathrm{NaOH}=0 \cdot 14$ per cent. $\mathrm{P}$.

$$
\mathrm{N}: \mathbf{P}=14: 1 \text {. }
$$

These results proved that the phosphatide present could not be of the nature of the diamino-monophosphatide found by Erlandsen in heart muscle.

An endeavour was made to decompose the cadmium chloride compound in order to investigate the phosphatide set free, but the amount of substance at my disposal was too small to give a definite result.

Another sample of cadmium chloride phosphatide prepared from the substance $(m)$ was washed very thoroughly with alcohol and gave the following figures:-

0.3590 gm. required 6.55 c.c. $\mathrm{N} / 10 \mathrm{H}_{2} \mathrm{SO}_{4}=2.50$ per cent. $\mathrm{N}$.

0.3120 gm. required 18.6 c.c. $\mathrm{N} / 2 \mathrm{NaOH}=3.3$ per cent. $P$.

$$
\mathrm{N}: \mathrm{P}=1 \cdot 6: 1 \text {. }
$$

It would thus seem that thorough washing of the cadmium compound does not materially alter the result.

As already mentioned, part of the substance $(m)$ became insoluble in alcohol after being kept for some time. This was dissolved in ether, precipitated by acetone and the nitrogen and phosphorus estimated. It contained 2.35 per cent. nitrogen and 3.46 per cent. phosphorus $=$ $\mathrm{N}: \mathrm{P} 1.5: 1$. On adding an alcoholic solution of cadmium chloride to 
an ethereal solution of this substance, a precipitate was obtained which had a $N: P$ ratio of $1 \cdot 2: 1$.

The inference drawn from these results was that the substance present was possibly a lecithin with a $N: P$ ratio of $1: 1$, for since the treatment with cadmium chloride caused such a marked difference in the nitrogen percentage of the substance it was quite probable that an impurity was present, all of which was not removed. Further purification of the substance, however, by dissolving in ether and precipitating with acetone did not appreciably change the nitrogen percentage, and it was obvious that a pure substance could not be obtained by this method.

\section{SUBSTANCE $(p)$}

This was also a lecithin-like body, but much whiter in appearance than the fraction described above. It had the properties and solubilities of ordinary lecithin.

Analyses gave the following results:-

$$
\text { Nitrogen }
$$

$0.6384 \mathrm{gm}$. used 25.5 c.c. $\mathrm{N} / 10 \mathrm{H}_{2} \mathrm{SO}_{4}=5.4$ per cent

$0.7544 \mathrm{gm}$. used $28 \cdot 25$ c.c. $\mathrm{N} / 10 \mathrm{H}_{2} \mathrm{SO}_{4}=5 \cdot 2$ per cent.

$$
\text { Average }=5 \cdot 3 \text { per cent. } \mathrm{N} \text {. }
$$

\section{Phosphorus}

0.5717 gm. used 28.35 c.c. $\mathrm{N} / 2 \mathrm{NaOH}=2.7$ per cent.

$0.4220 \mathrm{gm}$. used 22.74 c.c. $\mathrm{N} / 2 \mathrm{NaOH}=2.9$ per cent.

Average $=2 \cdot 8$ per cent. $P$.

$$
\mathrm{N}: \mathbf{P}=4 \cdot 2: 1 \text {. }
$$

This substance differed materially from substance $(m)$, the percentage of nitrogen being much higher and that of phosphorus being considerably lower. This result also suggested that the substance was impure, but owing to lack of material a cadmium chloride combination could not be investigated.

Some of these experiments were repeated with other samples of phosphatides obtained by alcohol extraction in the manner described. It was found, however, that fractions corresponding to $(m)$ and $(p)$ contained different amounts of nitrogen from these fractions. This was taken as strong evidence that the phosphatide of the alcoholic extract contained impurities which had not hitherto been separated by any of the methods in use at present. After many attempts at purification of this lipoid, a 
method was at last found which solved all the difficulties and showed that the different results obtained were really due to the presence of nitrogenous impurities.

\section{Purification of the Phosphatides of the Alcoholic Extract}

In the course of this investigation it was observed that when the residue of the alcoholic extract was shaken up with water, the fluid became coloured, suggesting that part of the substance had passed into solution. Since phosphatides are ordinarily insoluble in water, it was thought that extraction with water might result in a purer substance being obtained, since obviously something more than phosphatide was present.

Part of fraction $(m)$, described above, was therefore treated as follows:- Several grammes were taken and rubbed up in a mortar with a small quantity of water. When the substance was thoroughly broken up, more water was gradually added, and a dilute aqueous emulsion obtained. To this was added a small amount of pure acetone, when a white substance at once separated out and floated on the surface of the fluid. This was easily skimmed off, when the water-acetone fluid was found to be yellow in colour. The white substance separated was subjected to the same process several times in order to ensure access of the water to the fatty lipoid particles. The final product was thoroughly extracted with pure acetone, ỏried and analysed. The result was exceedingly satisfactory, as it showed that a great deal of nitrogen was got rid of by this method, while at the same time the purified substance had a $N: P$ ratio of nearly $1: 1$.

Analyses of substance $(m)$, which had been treated three times with water and acetone, gave results very similar to those obtained from ordinary lecithin.

Nitrogen-

Analyses of purified substance

$0.3989 \mathrm{gm}$. used 5.8 c.c. $\mathrm{N} / 10 \mathrm{H}_{2} \mathrm{SO}_{4}=2 \cdot 1$ per cent.

$0.4770 \mathrm{gm}$. used 7 c.c. $\mathrm{N} / 10 \mathrm{H}_{2} \mathrm{SO}_{4}=2.06$ per cent.

Average $=2.08$ per cent. $\mathrm{N}$.

Phosphorus-

0.3800 gm. used $26 \cdot 6$ c.c. $\mathrm{N} / 2 \mathrm{NaOH}=3.88$ per cent

$0.2158 \mathrm{gm}$. used 15 c.c. $\mathrm{N} / 2 \mathrm{NaOH}=3.9$ per cent.

Average $=3.9$ per cent. $P$.

$\mathrm{N}: \mathrm{P}=1 \cdot 18: 1$. 
Thus a substance having originally a $N: P$ ratio of $3: 1$ and containing 4.9 per cent. nitrogen had, after being three times treated as above described, only about 2 per cent. nitrogen and a $N: P$ ratio of $1 \cdot 18: 1$.

After being emulsified and precipitated six times it gave the same figures as ordinary lecithin.

\section{Nitrogen}

$0 \cdot 6516 \mathrm{gm}$. used 9.2 c.c. $\mathrm{N} / 10 \mathrm{H}_{2} \mathrm{SO}_{4}=1.97$ per cent. $\mathrm{N}$.

\section{Phosphorus}

0.2900 gm. used $21 \cdot 3$ c.c. $\mathrm{N} / 2 \mathrm{NaOH}=4.07$ per cent. $\mathrm{P}$.

$$
N: \mathbf{P}=1 \cdot 07: 1 \text {. }
$$

This proved that the ether soluble lecithin-like substance present in the alcohol extract of the kidney is really a monamino-monophosphatide and not a diamino-monophosphatide as described by Erlandsen in heart muscle. This point is further discussed in the following paper ' $O n$ the purification of phosphatides.'

\section{White Substance $(d)$}

This white substance isolated as described formed on drying a whitish yellow non-hygroscopic powder. Before making any attempt to purify it, an analysis was made, which showed that it was probably an impure substance.

\section{Nitrogen}

$0.3076 \mathrm{gm}$. used 6.6 c.c. $\mathrm{N} / 10 \mathrm{H}_{2} \mathrm{SO}_{4}=3$ per cent. $\mathrm{N}$.

\section{Phosphorus}

$0.4020 \mathrm{gm}$. used 13.45 c.c. $\mathrm{N} / 2 \mathrm{NaOH}=1.85$ per cent. $\mathrm{P}$.

$$
\mathrm{N}: \mathbf{P}=3.6: 1 \text {. }
$$

This impure substance was partly soluble in benzene, and in chloroform, from which it was precipitated by acetone; it was slightly soluble in ether, and gave Lassaigne's test for nitrogen and the ammonium molybdate test for phosphorus. After boiling with weak $\mathrm{HCl}$ it reduced Fehling's solution. No glycogen reaction was obtained, and Millon's protein reaction was also negative. In $\mathrm{H}_{2} \mathrm{O}$ part of it seemed to dissolve; the aqueous solution contained abundance of chlorides but no sulphates. The substance was now shaken up with water several times until the filtrate gave no chloride reaction. On testing the 
aqueous filtrate it was found to contain a considerable amount of nitrogen. This treatment of the substance with water was very tedious on account of the difficulty of filtration. The addition of water to the powder gave rise to a more or less sticky opalescent mass like thick starch paste, which quickly closed up the pares of the filter paper. The use of the centrifuge evaded this difficulty to some extent, but as the washing proceeded, precipitation was very incomplete, probably due to the absence of salts, and some loss of substance was unavoidable.

Analyses of the purified substance showed that it differed materially from the crude material.

\section{Analyses}

$0 \cdot 1190 \mathrm{gm}$. substance gave $0.2980 \mathrm{gm} . \mathrm{CO}_{2}=68 \cdot 3$ per cent. $\mathrm{C}$ and $0.1335 \mathrm{gm}: \mathrm{H}_{2} \mathrm{O}=12 \cdot 46$ per cent. $\mathrm{H}$.

Nitrogen

0.3586 gm. used $7 \cdot 7$ c.c. $\mathrm{N} / 10 \mathrm{H}_{2} \mathrm{SO}_{4}=3$ per cent. $\mathrm{N}$.

\section{Phosphorus}

$0 \cdot 2346 \mathrm{gm}$. used 14.55 c.c. $\mathrm{N} / 2 \mathrm{NaOH}=3.44$ per cent. $\mathrm{P}$.

$$
\mathrm{N}: \mathrm{P}=1.93: 1 \text {. }
$$

Thus a substance was obtained which had a nitrogen phosphorus ratio of almost exactly $2: 1$, and was probably the same subotance as that described under the ether extract.

\section{Properties}

This white substance formed a tasteless and odourless powder, which was non-hygroscopic and preserved its properties after being exposed to the air for a considerable time. It was practically insoluble in cold or hot ether, but easily dissolved in ethyl alcohol, especially on heating; from concentrated alcoholic solution it separated on cooling to room temperature. It was insoluble in acetane but soluble in hot methyl alcohol, from which it crystallised out on cooling, as in the case of ethyl alcohol. In chloroform, benzene, glacial acetic acid and pyridine, it dissolved at ordinary temperature but very easily on heating. With water it formed an opalescent starch-like mixture, from which it was precipitated by the addition of acetone. On boiling for some time with weak $\mathrm{HCl}$ it reduced Fehling's solution, decolourised safranin, and gave all the ordinary sugar reactions. It contained no sulphur.

The alcoholic solution was neutral and gave a precipitate with cadmium chloride and with platinum chloride, also with lead acetate. 
On boiling with acids it yielded a substance which formed a double salt with platinum chloride and gave the reactions of choline. The amount obtained was much less than that represented by the nitrogen present, amounting to somewhat less than 50 per cent. of the theory. No glycerine could be obtained, but owing to the relatively small amount of substance isolated and the difficulties of testing for this substance, no definite statement as to its absence can be made.

On hydrolysis, about 65 per cent. of fatty acids were obtained. The existence in the tissues of substances similar to the above was first suggested by Thudichum, who isolated from the brain three substances which he named apomyelin, sphingomyelin and amidomyelin.

Substances of this nature were afterwards described by Stern and Thierfelder, who isolated a diamino-monophosphatide from egg yolk, and by Erlandsen, who found a somewhat similar substance in heart muscle. Dunham and Jacobson also obtained a substance from ox kidney, which had a nitrogen phosphorus ratio of $3: 1$, but in other respects was very similar to certain of the above substances.

It has already been shown that the so-called diamino-monophosphatide isolated by Erlandsen was probably a mixture, as from a similar substance prepared from the kidney I succeeded in obtaining ordinary lecithin with a nitrogen to phosphorus ratio of $1: 1$. Erlandsen's substance also differed from the above in its physical properties, and especially in the fact that it was soluble in ether. The bodies described by Thudichum as sphingomyelin and amidomyelin were both in many respects similar to the substance isolated by me. In ether and cold alcohol they were only very slightly soluble and were precipitated from alcoholic solution by cadmium chloride. Amidomyelin was further described as a substance which on drying in vacuo formed a white mass which could be easily powdered, while sphingomyelin did not form a sticky mass, but was also capable of forming a powder. The properties of amidomyelin are not given. The diamino-monoplosphatide described by Stern and Thierfelder agrees in analyses and properties almost exactly with my substance, the most marked difference being that it did not reduce Fehling's solution on boiling.

As the reduction with Fehling's solution is not very marked and is only obtained distinctly when a comparatively large amount of the substance is taken, it is not possible to say at present whether this reaction is due to traces of impurity or is really dependent on a carbohydrate radicle incorporated in the molecule. 
The following table shows the results of analyses of these different diamino-monophosphatides.

\begin{tabular}{|c|c|c|c|c|c|c|c|c|c|}
\hline & & & & Substance & $\begin{array}{c}\text { Substance } \\
\text { from } \\
\text { heart }\end{array}$ & Sub & $\begin{array}{l}\text { tances fron } \\
\text { Thudichun }\end{array}$ & brain & Substance \\
\hline & & & $\begin{array}{l}\text { horse } \\
\text { kidney } \\
\text { MacLean) }\end{array}$ & $\begin{array}{l}\text { (Stern and } \\
\text { Thier- } \\
\text { felder) }\end{array}$ & $\begin{array}{l}\text { reckoned } \\
\text { from } \\
\text { CdCl }_{2} \\
\text { compound }\end{array}$ & $\begin{array}{c}\text { Apo- } \\
\text { myelin }\end{array}$ & $\underset{\text { Sphingo- }}{\text { Syelin }}$ & $\begin{array}{c}\text { Amido- } \\
\text { myelin }\end{array}$ & $\begin{array}{l}\text { (Dunham } \\
\text { and } \\
\text { Jacobson) }\end{array}$ \\
\hline C & $\ldots$ & $\ldots$ & $68 \cdot 19$ & 68.13 & $59 \cdot 48$ & 67.01 & $65 \cdot 37$ & $62 \cdot 4$ & $67 \cdot 12$ \\
\hline H & $\ldots$ & $\ldots$ & $12 \cdot 37$ & $12 \cdot 14$ & $9 \cdot 42$ & $11 \cdot 35$ & $11 \cdot 29$ & - & 11.54 \\
\hline $\mathbf{N}$ & $\ldots$ & $\ldots$ & $3 \cdot 0$ & $2 \cdot 77$ & 3.47 & $\mathbf{3} \cdot \mathbf{0}$ & $2 \cdot 96$ & - & $2 \cdot 84$ \\
\hline $\mathbf{P}$ & $\ldots$ & $\ldots$ & $3 \cdot 44$ & $3 \cdot 22$ & 3.84 & $3 \cdot 23$ & $\mathbf{3 \cdot 2 4}$ & - & $2 \cdot 18$ \\
\hline $\mathrm{N}$ & & $\ldots$ & $1.93: 1$ & $1.9: 1$ & $2: 1$ & $2: 1$ & $2: 1$ & - & $2 \cdot 9: 1$ \\
\hline
\end{tabular}

\section{Carnaubon}

This substance, which was described by Dunham and Jacobson as a triamino-monophosphatide, possesses all the properties of the substance isolated from the horse kidney. It is the most fully described and investigated of this class of substances and its composition is given as similar to lecithin, but having, instead of glycerine, another bodygalactose - to which the fatty acids are attached. The acids isolated were carnaubic acid, stearic acid, and palmitic acid. Though described as a triamino-monophosphatide, the authors agree that the $\mathrm{N}: \mathrm{P}$ ratio was often about $7: 3$, and consider the possibility of the substance being impure. In the light of the results of the present investigation, it seems probable that the substance was a diamino-monophosphatide, which treatment with water as above described would have purified.

If so, the question of these ether insoluble phosphatides is much simplified, for the available evidence suggests that all the substances of this nature hitherto isolated are of the nature of diamino-monophosphatides, and are probably identical in structure with pure carnaubon. In order to make certain that the substance isolated from horse kidney was really a diamino-monophosphatide, two more samples were prepared by different methods.

\section{SAMPLE II}

This sample was prepared in the same way as that described by Dunham and Jacobson, only it was finally extracted with water. Fresh kidneys were treated with hot 95 per cent. alcohol and the extract 
discarded. The residue was extracted first with 95 per cent., and then with 85 per cent. alcohol, and the mixed solutions filtered hot. They were then left to stand in the ice-room. The precipitate formed was collected, dried and dissolved in benzene, the solution filtered, and the benzene evaporated off by distillation under reduced pressure. The syrup obtained was thoroughly mixed with ether and left to stand, when a white precipitate separated. The ether was syphoned off and the residue washed with more ether. It was then dissolved in hot alcohol and left to stand, when a white substance separated out. This was treated with ether, dried in vacuo and extracted with several changes of water as described above. This final treatment with water is important, as otherwise a pure substance is not obtained. The resulting product gave the following figures on analysis:-

\section{Analyses}

$0 \cdot 1025 \mathrm{gm}$. substance gave $0.2567 \mathrm{gm} . \mathrm{CO}_{2}=68 \cdot 29$ per cent. C. and $0 \cdot 1132 \mathrm{gm} . \mathrm{H}_{2} \mathrm{O}=12 \cdot 26$ per cent. $\mathrm{H}$.

Nitrogen-

$0.3806 \mathrm{gm}$. used $7 \cdot 8$ c.c. $\mathrm{N} / 10 \mathrm{H}_{2} \mathrm{SO}_{4}=2 \cdot 9$ per cent. $\mathrm{N}$. Phosphorus-

$0 \cdot 2380$ gm. used 14 c.c. $\mathrm{N} / 2 \mathrm{NaOH}=3.3$ per cent. $\mathrm{P}$. $\mathrm{N}: \mathrm{P}=1.95: 1$.

\section{SAMPLE III}

This substance was prepared as follows:-The crude alcoholic extract of the kidneys was evaporated to a syrup, excess of acetone added, and the precipitate rubbed up with ether, when an opalescent mixture was obtained. On centrifuging, a white precipitate separated. This white substance was thoroughly extracted with ether and centrifuged three times. The residue was dissolved in hot alcohol and filtered hot. The filtrate, however, was not quite clear, so it was again filtered and a perfectly clear solution obtained; a small quantity of a sticky substance, insoluble in alcohol and in ether, remained on the bottom of the flask.

This clear solution was allowed to stand, and the white substance which separated filtered off and dried. It was then emulsified with water, and after the addition of some acetone, left to stand for twenty-four hours, when a flocculent white precipitate was obtained. This process was repeated twice and the final product dried and analysed. It had the same composition as the two substances formerly described. 


\section{Analyses}

$0.1321 \mathrm{gm}$. substance gave $0.3292 \mathrm{gm} . \mathrm{CO}_{2}=68 \cdot 0$ per cent. $\mathrm{C}$ $0 \cdot 1321 \mathrm{gm}$. substance gave $0 \cdot 1475 \mathrm{gm} . \mathrm{H}_{2} \mathrm{O}=12 \cdot 4$ per cent. $\mathrm{H}$. Nitrogen-

$0 \cdot 1591 \mathrm{gm}$. used $3 \cdot 3$ c.c. $\mathrm{N} / 10 \mathrm{H}_{2} \mathrm{SO}_{4}=2 \cdot 9$ per cent. $\mathrm{N}$. Phosphorus-

$0 \cdot 1300$ gm. used 8 c.c. $\mathrm{N} / 2 \mathrm{NaOH}=3 \cdot 4$ per cent. $\mathrm{P}$.

$$
\mathrm{N}: \mathbf{P}=1.9: 1 \text {. }
$$

Both these substances had the same properties as the one first described.

A comparison of their analyses shows that this substance was certainly a diamino-monophosphatide.

Comparison of Thrie Samples of Diammo-monophosphatide

\begin{tabular}{ccccccc} 
& & & No. 1 & No. 2 & No. 3 & Average \\
C & $\ldots$ & $\ldots$ & 68.3 & 68.29 & 68.0 & 68.19 \\
H & $\ldots$ & $\ldots$ & 12.46 & $12 \cdot 26$ & 12.4 & 12.37 \\
N & $\ldots$ & $\ldots$ & 3.0 & 2.9 & 2.9 & 2.93 \\
P & $\ldots$ & $\ldots$ & $3 \cdot 44$ & $3 \cdot 3$ & 3.4 & 3.38 \\
\hline N $:$ P ratio & $1.9: 1$ & $1.95: 1$ & $1.9: 1$ & $1.92: 1$
\end{tabular}

Since the white substance present in the ether extract agrees with this in composition and properties, it shows that this substance is identical with that described above.

Consideration of the properties of this substance suggest that part of it would be present in the ethereal extract.

\section{General Summary}

The ethereal extract of the horse kidney contains three phosphatides lecithin, cuorin, and a diamino-monophosphatide. The subsequent alcoholic extract also contains a diamino-monophosphatide, which is the same as that obtained in very small amount from the ether extract. This substance is but very slightly soluble in ether, but there is a good deal of evidence to show that it is fairly soluble in an ethereal solution of lecithin. Thus, if the crude phosphatide residue of the ethereal extract of kidney is taken and extracted with ether, a very opalescent mixture is at first obtained, but as the lipoids present dissolve, the solution becomes much clearer. On centrifuging, a perfectly clear ethereal solution is obtained, but if the ether be evaporated off and the residue again extracted with ether, the solution so obtained is by no means clear, and some more 
white substance can be separated by the centrifuge; if, however, the solution is allowed to stand for some time before centrifuging, it may become quite clear. Again, when it seems as if all the white substance had been got rid of, it often happens that the addition of ether to the lipoid residue gives a solution which becomes clear only after some little time. This property of the diamino-monophosphatide suggests the probability that every sample of lecithin prepared from tissues containing this substance was contaminated by it, and it is difficult to see how complete separation can be achieved, though careful treatment with ether and quick centrifuging undoubtedly gets rid of all but traces. This substance is entirely different from lecithin and other lipoids in its physical properties, as it forms a white non-hygroscopic powder, and not a more or less sticky mass, as is seen in the case of lecithin and cuorin.

Owing to its greater solubility in alcohol, the majority of it is found in the alcoholic extract, but it is present only in comparatively small amount, and is not to be confounded with the substance found by Erlandsen in the alcoholic extract of heart muscle. Erlandsen's substance possessed all the properties of ordinary lecithin and was quite soluble in ether; it constituted also the chief bulk of the phosphatides present in the alcoholic extract. A corresponding substance is present in the kidney in comparatively large amount, but its analyses did not quite compare with that of heart muscle, and on subjecting it to purification by means of $\mathrm{H}_{2} \mathrm{O}$ and acetone, it was found to be of the nature of ordinary lecithin, with a nitrogen to phosphorus rato of $1: 1$.

Thus the lipoids of the alcoholic extract of kidney are the same as the alcohol soluble ones contained in the ethereal extract; the alcohol insoluble substance cuorin, very soluble in ether, is naturally present in the ether extract. The alcohol extract contains other bodies with a high percentage of nitrogen, but these are soluble in water and may be separated in the manner described. The water soluble substances contain only a small amount of phosphorus and are not of the nature of ordinary phosphatides; their nitrogen percentage is very high. From these observations it follows that the subject of the kidney lipoids has been much simplified, and an extension of these results to other organs and tissues will probably show that many of the substances hitherto described as containing large percentages of nitrogen are really mixtures of simpler bodies with these nitrogenous water-soluble bodies mentioned above. Other tissues such as heart muscle, liver and egg yolk, are at present being investigated from this point of view. 


\section{Conclusions}

(1) The acetone insoluble phosphatides of the horse kidney are lecithin, cuorin, and a diamino-monophosphatide-carnaubon.

All these are contained in the primary ether extract, while the subsequent alcoholic extract contains lecithin and carnaubon; cuorin, being insoluble in alcohol, is not present here. Thus, so far as solubility allows, the lipoids of the ether extract are the same as those present in the alcoholic extract.

(2) In the kidneys investigated, the ethereal extract contained much more cuorin than lecithin.

(3) A method is described whereby the complicated alcoholic extract can be purified from a nitrogenous substance. In all tissues investigated hitherto, the phosphatides of the alcoholic extract must have been contaminated by this substance; this explains many of the divergent results obtained.

(4) The diamino-monophosphatide isolated has all the properties of a substance found in ox kidney by Dunham and Jacobson, and called by them carnaubon. They state that this substance is a triaminomonophosphatide.

(5) It is probable that carnaubon is not a tri-, but a diaminomonophosphatide, and that the methods used for its isolation by Dunham and Jacobson were inefficient to obtain a pure substance. On extracting a substance obtained by the method employed by the above investigators with water, a diamino-monophosphatide was obtained.

\section{REFERENCES}

1. Erlandsen, Ztsch. f. physiol. Chem., LI, p. 71, 1907.

2. Stern and Thierfelder, Ztsch. f. physiol. Chem., LIII, p. 379, 1907.

3. MacLean, Ztsch. f. physiol. Chem., LVII, p. 304, 1908.

4. Fränkel, Bio-Chem. Ztsch., XIX, p. 262, 1909.

5. Baskoff, Ztsch. f. physiol. Chem., LVII, p. 395, 1908.

6. Thudichum, Physiological Chemistry of the Brain.

7. Dunham and Jacobson, Ztsch. f. physiol. Chem., LXIV, p. 303, 1910. 